\title{
Alain Corbellari, La voix des clercs. Littérature et savoir universitaire autour des dits du XIII ${ }^{\mathrm{e}}$ siècle
}

\section{Giuseppe Noto}

\section{OpenEdition}

\section{Journals}

\section{Edizione digitale}

URL: http://journals.openedition.org/studifrancesi/9115

DOI: 10.4000/studifrancesi.9115

ISSN: 2427-5856

\section{Editore}

Rosenberg \& Sellier

\section{Edizione cartacea}

Data di pubblicazione: 1 juin 2008

Paginazione: 160

ISSN: 0039-2944

\section{Notizia bibliografica digitale}

Giuseppe Noto, «Alain Corbellari, La voix des clercs. Littérature et savoir universitaire autour des dits du XIII' siècle», Studi Francesi [Online], 154 (LII | I) | 2008, online dal 30 novembre 2015, consultato il 11 janvier 2021. URL: http://journals.openedition.org/studifrancesi/9115 ; DOI: https://doi.org/10.4000/ studifrancesi.9115

Questo documento è stato generato automaticamente il 11 janvier 2021.

\section{(c) (i) (9)}

Studi Francesi è distribuita con Licenza Creative Commons Attribuzione - Non commerciale - Non opere derivate 4.0 Internazionale. 


\title{
Alain Corbellari, La voix des clercs. Littérature et savoir universitaire autour des dits du XIII siècle
}

\author{
Giuseppe Noto
}

\section{NOTIZIA}

ALAIN CORBELLARI, La voix des clercs. Littérature et savoir universitaire autour des dits du XIII ${ }^{e}$ siècle, Genève, Librairie Droz, 2005 («Publications romanes et françaises» fondées par Mario Roques, aujourd'hui dirigées par Pierre-Yves Badel, CCXXXVI), pp. 341.

1 Il volume si prefigge di 'leggere' l'opera di Henri de Valenciennes, Henri d'Andeli e Rutebeuf - nonché dei loro principali epigoni - all'interno del processo (che trova il suo compimento nel xiI secolo, ma va analizzato nella lunga durata) di affermazione della letteratura francese su quella latina.

2 L'autore sottolinea in particolare come nelle dinamiche di quel processo si imponga rapidamente come protagonista la figura del clerc, il detentore per eccellenza nel Medioevo del sapere e della scrittura, portatore di una 'parola' differente sia da quella (essenzialmente orale) del prete e del giullare sia da quella (scritta) del romanziere: di qui la proposta di analizzare la voix des clercs come si ritrova nella produzione letteraria 'clericale', che si caratterizza innanzi tutto per la sua volontà di emanciparsi tanto dai valori cortesi quanto dal potere religioso.

3 Lo studio prende in considerazione soprattutto lo strumento letterario principe attraverso il quale la voce del clerc (o meglio dell'io del clerc-scrittore) si fa intendere, ovvero il dit, genere che per statuto si presta alle più svariate forme del discorso 'personale'. E tuttavia lo sguardo di Corbellari spazia sempre all'interno del più generale contesto culturale, ovvero all'interno di quel milieu (per intenderci e per comprendere la portata dell'analisi condotta) che ha visto fiorire le opere, oltre che dei già citati Henri de Valenciennes, Henri d'Andeli e Rutebeuf, anche di Philippe le 
Chancelier, Richard de Fournival, Adam de la Halle, non senza che il ragionamento si allarghi, ove opportuno, a Jean de Meun ed agli autori dei tempi di Filippo il Bello e, a ritroso, a Jean Bodel ed alla produzione mediolatina del XII secolo.

4 Il merito principale del saggio è a mio avviso quello di enucleare con precisione ed analizzare con acribia ed intelligenza i temi chiave della letteratura 'clericale' ( $\mathrm{i}$ malheurs dell'intellettuale, la donna tentatrice e divoratrice, il vino, la città di Parigi ed il suo ruolo, il mondo universitario, il mito del sapere), interpretandoli come espressione di una volontà di rottura nei confronti della 'committenza' (o, se si preferisce, del potere economico), e giungendo in questo modo a fare chiarezza sullo statuto e sulla funzione del gruppo di intellettuali (l'autore a più riprese parla di «caste») che di norma etichettiamo come clercs: gruppo davvero difficile da definire in termini precisi dal punto di vista sociologico e culturale (sfuggente com'è alle 'moderne' categorie con le quali spesso si tenta di afferrarlo) ma sicuramente protagonista di una «révolte» (p. 17) che lo vede rivendicare per il proprio lavoro uno spazio completamente nuovo, che diverrà poi (e questa è una delle suggestioni più interessanti del volume di Corbellari) quello più propriamente definibile come lo spazio della letteratura, dotato di una nuova parola poetica e di nuovi codici letterari, che, tra l'altro, cristallizzano, e offrono alla posterità, tutta una serie di temi sparsi nella letteratura del XII secolo sia mediolatina sia in volgare: si pensi, ad esempio, a certe immagini della donna legate all'antinomia idealizzazione-repulsione o a certe caratterizzazioni della città-capitale come luogo della costruzione della gloria futura.

Il volume ha l'accessorio (ma non secondario) merito di approfondire alcune delle più recenti acquisizioni critiche sulla produzione letteraria del xIII secolo in lingua d'oil (si discute ampiamente, per citare un solo caso, della paternità del Lai d'Aristote, da attribuire con ogni probabilità ad Henri de Valenciennes e non ad Henri d'Andeli) e di pubblicare in appendice (con un apparato forse troppo scarno di note esegetiche ed esplicative: utile comunque l'indice dei «Termes glosés en notes» a p. 295) alcuni dits sinora inediti ed altri le cui precedenti e più recenti edizioni risultano di parecchi decenni fa e comunque oramai difficili da reperire.

6 Molto ricca e ben organizzata la bibliografia esibita nelle note e al fondo del volume. 